\title{
Toll-like receptor 3 ligand-induced antiviral response in mouse osteoblastic cells
}

\author{
KIMIYA NAKAMURA ${ }^{1}$, YOSHIAKI DEYAMA ${ }^{2}$, YOSHITAKA YOSHIMURA ${ }^{2}$, \\ KUNIAKI SUZUKI $^{2}$ and MANABU MORITA ${ }^{1}$ \\ ${ }^{1}$ Department of Preventive Dentistry, Division of Oral Health Science, ${ }^{2}$ Department of Molecular Cell Pharmacology, \\ Division of Oral Pathobiological Science, Hokkaido University Graduate School of Dental Medicine, \\ Kita 13 Nishi 7, Kita-ku, Sapporo 060-8586, Japan
}

Received December 4, 2006; Accepted January 17, 2007

\begin{abstract}
Double-stranded RNA (dsRNA) and its mimic, polyinosinic acid:polycytidylic acid $[\operatorname{poly}(\mathrm{I})$ : $\operatorname{poly}(\mathrm{C})]$, are recognized by toll-like receptor 3 (TLR3) that induces the production of IFN- $\beta$ in many cell types. In the present study, we investigated the effects of $\operatorname{poly}(\mathrm{I}): \operatorname{poly}(\mathrm{C})$ on mouse osteoblastic MC3T3-E1 (E1) cells. Poly(I):poly(C) markedly increased IFN- $\beta$ mRNA level in a dose-dependent manner. The increase in the IFN- $\beta$ mRNA level was apparent as early as $1 \mathrm{~h}$ after adding poly(I):poly(C) to the culture and peaked at $12 \mathrm{~h}$. Stimulation with $\operatorname{poly}(\mathrm{I}): \operatorname{poly}(\mathrm{C})$ enhanced the expression of CXCL10 mRNA and TLR3 in E1 cells. Moreover, poly(I):poly(C) induced tyrosine phosphorylation of the transcription factor STAT1 in E1 cells. An anti-IFN- $\beta$ neutralizing antibody partially inhibited poly(I):poly(C)induced CXCL10 mRNA, TLR3 mRNA and STAT1 phosphorylation. These results indicate that osteoblasts secrete IFN- $\beta$ in response to viral infection and that endogenous IFN- $\beta$ induces both CXCL10 and TLR3 production via an IFN- $\alpha / \beta$ receptor-STAT1 pathway. It is suggested that osteoblasts are involved in host defense as well as bone metabolism.
\end{abstract}

\section{Introduction}

Osteoblasts are specialized cells responsible for bone formation in vertebrates. Bone tissues mainly consist of hydroxyapatite crystals and various kinds of bone matrix proteins, including type I collagen, osteocalcin, osteopontin,

Correspondence to: Dr Yoshiaki Deyama, Department of Molecular Cell Pharmacology, Division of Oral Pathobiological Science, Hokkaido University Graduate School of Dental Medicine, Kita 13 Nishi 7, Kita-ku, Sapporo 060-8586, Japan

E-mail: dey@den.hokudai.ac.jp

Key words: osteoblast, polyinosinic acid:polycytidylic acid, interferon- $\beta$, CXCL10, toll-like receptor 3 osteonectin and bone sialoprotein. Most of these bone matrix proteins are secreted and deposited by mature osteoblasts $(1,2)$. Moreover, osteoblasts play a central role in the modulation of the differentiation and activity of osteoclasts (3). Osteoblasts express the receptor activator of NF-кB ligand (RANKL), a member of the tumor necrosis factor (TNF) family that is induced as a membrane-associated protein in osteoblasts/stromal cells in response to many bone resorbing factors. The binding of RANKL to its receptor RANK on precursor cells results in osteoclastogenesis $(4,5)$.

Toll-like receptors (TLRs) are a family of mammalian proteins homologous to Drosophila Toll, and there are 10 (TLRs 1-10) and 12 (TLRs 1-9 and 11-13) family members in humans and mice, respectively (6). Peptidoglycan (PGN), double-stranded RNA (dsRNA), lipopolysaccharide (LPS), flagellin, and the CpG motif of unmethylated DNA (CpG DNA) are ligands of TLR2, TLR3, TLR4, TLR5, and TLR9, respectively (7-11). Among these ligands, dsRNA and polyinosinic acid:polycytidylic acid $[\operatorname{poly}(\mathrm{I}): \operatorname{poly}(\mathrm{C})]$, a synthetic dsRNA analogue, are able to induce production of IFN $-\alpha / \beta$ in many cell types (12-14).

IFN- $\beta$ is produced by various types of cells in response to viral and bacterial infections $(15,16)$ and regulates cellular immune response to viral and bacterial infections $(17,18)$. IFN- $B$ also regulates bone metabolism. Bone metabolism is regulated by a mechanism that balances bone formation and resorption, in which bone-forming osteoblasts and boneresorbing osteoclasts play central roles $(19,20)$. Recently, it was demonstrated that RANKL up-regulated the expression of IFN- $\beta$ mRNA in bone marrow-derived macrophages as osteoclast precursor cells and that IFN- $\beta$ inhibited osteoclast differentiation by interfering with the RANKL-induced expression of c-Fos, an essential transcription factor for the formation of osteoclasts (21). Although osteoclast progenitors are known to constitutively express IFN- $\beta$, it remains unclear whether osteoblasts produce IFN- $\beta$. Moreover, the function of osteoblasts in viral infection is not yet clear.

In the present study, we investigated the effects of poly(I):poly(C) on the mouse osteoblastic cell line MC3T3E1 (E1) cells. Poly(I):poly $(\mathrm{C})$ increased the expression levels of IFN- $B$, CXCL10, a member of the CXC chemokine family, and TLR3 mRNA in E1 cells. Moreover, poly(I):poly(C) 
induced tyrosine phosphorylation of the transcription factor STAT1 in E1 cells. An anti-IFN- 3 neutralizing antibody partially inhibited poly(I):poly(C)-induced CXCL10 mRNA and TLR3 mRNA expression and STAT1 activation. These results indicate that osteoblasts secrete IFN- $\beta$ in response to viral infection and that endogenous IFN- $\beta$ induces both CXCL10 and TLR3 production via an IFN- $\alpha / \beta$ receptorSTAT1 pathway. It is suggested here that osteoblasts are involved in host defense as well as bone metabolism.

\section{Materials and methods}

Reagents. Poly(I):poly(C) was obtained from GE Biosciences (Piscataway, NJ, USA). Recombinant mouse IFN- $B$ and rabbit polyclonal antibody against mouse IFN- $\beta$ were purchased from PBL Biomedical Laboratories (New Brunswick, NJ). Rabbit anti-TLR3 polyclonal antibody was obtained from Stressgen (Victoria, Canada). Mouse antiSTAT1 (N-terminus) antibody and mouse anti-phosphoSTAT1 antibody (pY701) were from BD Biosciences (San Diego, CA, USA).

Cell culture. Osteoblastic E1 cells from mouse calvaria were cultured in $\alpha$-minimum essential medium ( $\alpha$-MEM) supplemented with $10 \%$ fetal bovine serum (FBS), ascorbic acid $(50 \mu \mathrm{g} / \mathrm{ml})$, and kanamycin $(60 \mu \mathrm{g} / \mathrm{ml}$; Sigma). Cultures were maintained at $37^{\circ} \mathrm{C}$ under a humidified atmosphere with $5 \% \mathrm{CO}_{2}$ in air. After confluence, E1 cells were treated with poly(I):poly(C) or IFN-ß.

$R T-P C R$. Total RNA from E1 cells was prepared using TRIzol solution (Invitrogen, Carlsbad, CA) according to the manufacturer's protocol. First-strand cDNA was synthesized from total RNA with ReverTra Ace (Toyobo, Osaka, Japan) and was subjected to PCR amplification with AmpliTaq Gold DNA polymerase (Roche Molecular Systems, Braunchburg, $\mathrm{NJ})$. Sequences of the primers used for PCR were as follows: IFN- $3,5^{\prime}-\mathrm{CTC}$ CAG CTC CAA GAA AGG ACG-3' and 5'GAA GTT TCT GGT AAG TCT TCG-3'; CXCL10, 5'-CCT GCC CAC GTG TTG AGA T-3' and 5'-TGA TGG TCT TAG ATT CCG GAT TC-3'; TLR3, 5'-ATT TAG AGT CCA ACG GCT TAG ATG-3' and 5'-TTC CAG TAA AAA GAG ATC CTC CAG-3'; IFN- $\alpha / \beta$ receptor (IFNAR), 5'-CAT GGC TGG CTA TAT TGT TCC-3' and 5'-ATG GCT TGG GTT AAA GGT TTA C-3'; and glyceraldehyde-3-phosphate dehydrogenase (G3PDH), 5'-CGG AGT CAA CGG ATT TGG TCG TAT-3' and 5'-AGC CTT CTC CAT GGT GGT GAA GAC-3'. Amplification was conducted for 23-37 cycles. All PCRs were within the exponential amplification range. The annealing temperatures of IFN- $\beta$, TLR3, CXCL10, IFNAR and G3PDH were $62,55,55,54$ and $60^{\circ} \mathrm{C}$, respectively. After amplification, the synthesized PCR products were separated by electrophoresis on a $1 \%$ agarose gel and visualized by ethidium bromide staining. The levels of expression of IFN- 3, CXCL10 and TLR3 mRNA were analyzed with Scion Image (Scion Corp., MD) and normalized with G3PDH mRNA expression.

Western blot analysis. After various treatments, E1 cells were washed twice with PBS and then treated with lysis
A

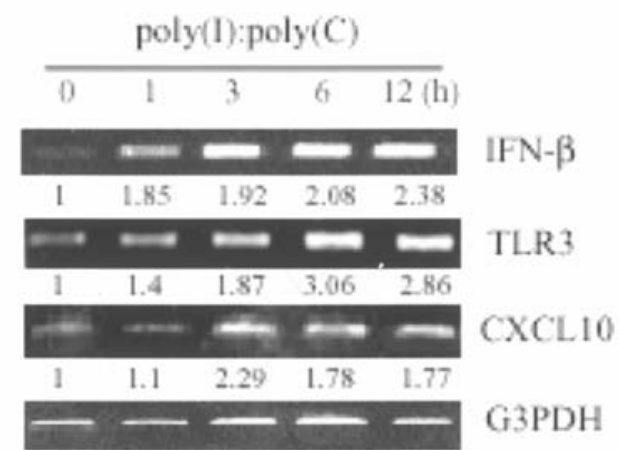

B

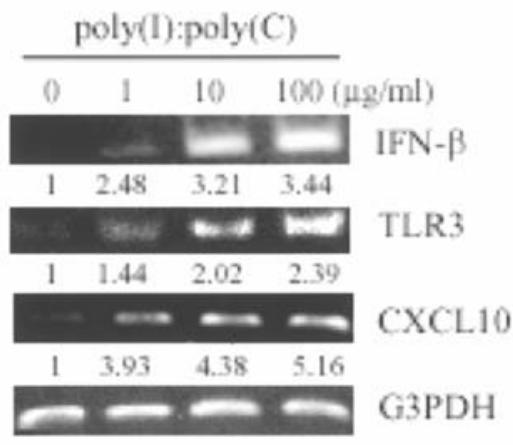

C

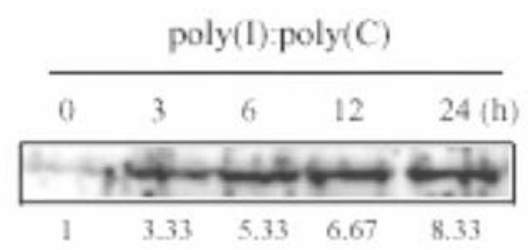

TLR3

Figure 1. Poly(I):poly(C) induced the expression of IFN- $\beta$ mRNA, CXCL10 mRNA and TLR3 in MC3T3-E1 cells. (A) E1 cells were cultured in $\alpha$-MEM with $100 \mu \mathrm{g} / \mathrm{ml}$ poly(I):poly(C) for the indicated periods, and total RNA was analyzed by RT-PCR with specific primers described in Materials and methods. G3PDH was used as an internal control. Fold increase at the bottom of the signals represents the intensity of IFN- 3 , CXCL10 and TLR3 mRNA expression relative to G3PDH. (B) E1 cells were exposed to various concentrations of poly(I):poly(C) for $6 \mathrm{~h}$. Levels of IFN-ß, CXCL10, TLR3 and G3PDH mRNA were determined as described in A. (C) E1 cells were stimulated with $100 \mu \mathrm{g} / \mathrm{ml} \operatorname{poly}(\mathrm{I}): \operatorname{poly}(\mathrm{C})$ for various periods, and whole cell lysates were extracted and subjected to $10 \%$ SDS-PAGE. TLR3 protein was visualized with anti-TLR3 antibody and an enhanced chemiluminescence system. Figures at the bottom of the signals indicate the intensity of TLR3 protein expression.

buffer [10 mM HEPES-KOH (pH 7.5), $100 \mathrm{mM} \mathrm{KCl}$ and $0.1 \%$ NP-40]. The protein concentration in the cell lysate was measured using a BioRad protein assay kit (BIORAD, Hercules, CA). Each sample containing equal amounts of protein was separated by $10 \%$ SDS-polyacrylamide gel electrophoresis (SDS-PAGE) and transferred to a polyvinylidene difluoride membrane (Millipore, Bedford, MA). After having been blocked with 5\% skim milk in TBST (Tris-buffered saline containing $0.1 \%$ Tween-20), the membrane was incubated with anti-TLR3, anti-STAT1 and anti-phospho-STAT1 antibodies and subsequently with HRPconjugated anti-mouse or anti-rabbit IgG antibody. Immunoreactive proteins were visualized with Western blot chemiluminescence reagents (PerkinElmer Life Sciences, Boston, MA) following the manufacturer's instructions. 
A

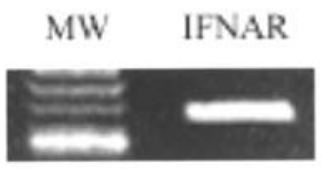

B
C

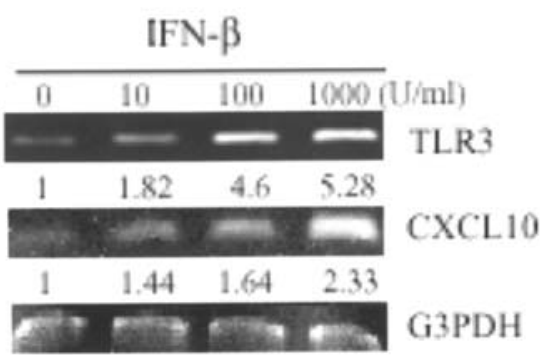

D

\begin{tabular}{|c|c|c|c|c|}
\hline 0 & 1 & 3 & 6 (h) & \multirow{2}{*}{ TLR3 } \\
\hline 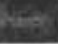 & $\cos 5$ & theses & ences & \\
\hline 1 & 1.41 & 1.72 & 1.89 & \multirow[b]{2}{*}{ CXCLI0 } \\
\hline & 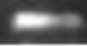 & neses & $\mathrm{me}$ & \\
\hline 1 & 3.03 & 1.92 & 1.83 & \multirow{2}{*}{ G3PDH } \\
\hline$=$ & 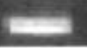 & 2 & 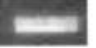 & \\
\hline
\end{tabular}

\begin{tabular}{|c|c|c|c|c|c|}
\hline poly (I) : poly (C) & - & 100 & 100 & 100 & $(\mu \mathrm{g} / \mathrm{ml})$ \\
\hline \multirow{5}{*}{ IFN- $\mathrm{A} A \mathrm{~b}$} & - & - & 100 & 1000 & $(\mathrm{NU} / \mathrm{ml})$ \\
\hline & 20 & $\cos$ & & news & TLR3 \\
\hline & 1 & 3.45 & 3.36 & 1.74 & \\
\hline & $A+2$ & can & $\cos$ & $=0$ & CXCL10 \\
\hline & 1 & 2.41 & 1.56 & 1.61 & \\
\hline
\end{tabular}

Figure 2. Exogenous IFN- $\beta$ induced the expression of TLR3 and CXCL10 mRNA in E1 cells. (A) PCR products corresponding to IFN- $\alpha / \beta$ receptor (IFNAR) were separated by electrophoresis on a $1 \%$ agarose gel and visualized by ethidium bromide staining. MW indicates molecular weight marker ( $\phi$ X174-HincII). (B) E1 cells were cultured in $\alpha$-MEM with $1000 \mathrm{U} / \mathrm{ml}$ recombinant mouse IFN- $\beta$, and total RNA was analyzed by RT-PCR with specific primers described in Materials and methods. (C) E1 cells were cultured with various concentrations of IFN- 3 for 6 h, and then TLR3, CXCL10 and G3PDH mRNA were analyzed by RT-PCR. Fold increase at the bottom of the signals represents the intensity of TLR3 and CXCL10 mRNA expression relative to G3PDH. (D) E1 cells were cultured with or without various concentrations of neutralizing antibody against IFN- 3 and $100 \mu \mathrm{g} / \mathrm{ml}$ of poly(I):poly(C) for $6 \mathrm{~h}$. CXCL10, TLR3 and G3PDH mRNA expression was analyzed by RT-PCR using specific primers described in Materials and methods. Figures at the bottom of CXCL10 and TLR3 mRNA images were normalized against expression of the G3PDH gene.

\section{Results}

Poly(I):poly $(C)$ increases IFN- $\beta, C X C L 10$, and TLR3 $m R N A$ expression levels in osteoblastic E1 cells. Poly(I):poly(C), a synthetic double-stranded RNA, acts on various cells to induce production of IFN- $\beta$, which is a key cytokine for antiviral responses (12-14). Therefore, we examined the induction of IFN- $\beta$ mRNA expression in E1 cells by poly(I):poly(C). As shown in Fig. 1A, poly(I):poly $(\mathrm{C})$ markedly increased the IFN- $\beta$ mRNA expression level in E1 cells. The increase in the IFN- $\beta$ mRNA level was apparent as early as $1 \mathrm{~h}$ after adding poly(I):poly(C) to the culture and peaked at $12 \mathrm{~h}$. Gasper et al (22) reported that Salmonella-derived LPS, a ligand of TLR4, could stimulate cultured mouse osteoblasts to express the mRNA encoding CXCL10 and induce secretion of this chemokine in a dose-dependent manner. We therefore examined whether the TLR3 ligand poly(I):poly(C) induced the expression of CXCL10 mRNA. RT-PCR analysis of E1 cells showed that poly(I):poly(C) induced CXCL10 mRNA expression. The CXCL10 mRNA level was clearly elevated at $3 \mathrm{~h}$ after the addition of poly(I):poly(C) (Fig. 1A). We also examined the time course of TLR3 mRNA expression in response to poly(I):poly(C). The TLR3 mRNA level was slightly elevated as early as $1 \mathrm{~h}$ after the addition of poly(I):poly(C) and peaked at $6 \mathrm{~h}$ (Fig. 1A). As shown in Fig. 1B, the effects of poly(I):poly(C) on IFN-B, CXCL10 and TLR3 mRNA were dose dependent. These effects were slightly enhanced at $1 \mu \mathrm{g} / \mathrm{ml} \operatorname{poly}(\mathrm{I}): \operatorname{poly}(\mathrm{C})$, and the maximal responses were obtained at $100 \mu \mathrm{g} / \mathrm{ml}$.

TLR3 ligand up-regulates production of TLR3 protein in osteoblastic E1 cells. To determine whether poly(I):poly(C) induces the production of TLR3 protein by E1 cells, total cellular protein was isolated at various times after stimulation with poly(I):poly(C), and the expression of TLR3 protein was analyzed by Western blotting. Concomitant with the induction of TLR3 mRNA expression, the results of Western blot analysis revealed that the expression level of TLR3 protein in E1 cells was markedly increased by poly(I):poly(C) treatment (Fig. 1C).

IFN- $\beta$ induces expression of TLR3 and CXCL1O $\mathrm{mRNA}$ in osteoblastic El cells. Doyle et al (23) revealed that stimulating primary macrophage cells with IFN- $\beta$ resulted in a dose-dependent up-regulation of TLR3 mRNA. Thus, we investigated whether exogenous IFN- $\beta$ could increase the level of TLR3 mRNA in osteoblastic cells. IFN- $\beta$ binds to IFN- $\alpha / \beta$ receptor (IFNAR). Therefore, we first examined whether E1 cells express the IFNAR mRNA. IFNAR mRNA was expressed in E1 cells (Fig. 2A). As shown in Fig. 2B, the effect of exogenous IFN- $\beta$ on TLR3 mRNA expression was time dependent. The TLR3 mRNA expression level increased as early as $1 \mathrm{~h}$ after stimulation with IFN- $B$ and peaked after $6 \mathrm{~h}$. Moreover, TLR3 mRNA expression was clearly observed at $10 \mathrm{U} / \mathrm{ml}$ and the maximal level was obtained at $1000 \mathrm{U} / \mathrm{ml}$ of IFN-ß (Fig. 2C). The CXCL10 mRNA level was clearly elevated as early as $1 \mathrm{~h}$ after the addition of IFN-B (Fig. 2B). As in the case of TLR3 mRNA expression, the effect of exogenous IFN- $B$ on CXCL10 mRNA was dose dependent (Fig. 2C).

Anti-mouse IFN- $\beta$ antibody partially inhibits poly(I):poly(C)induced TLR3 mRNA expression in osteoblastic E1 cells. To determine whether IFN- $B$ was responsible for the 
A

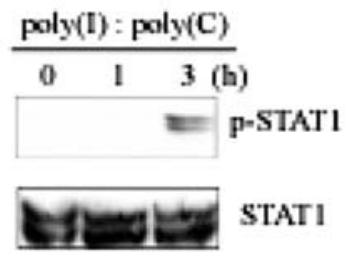

B

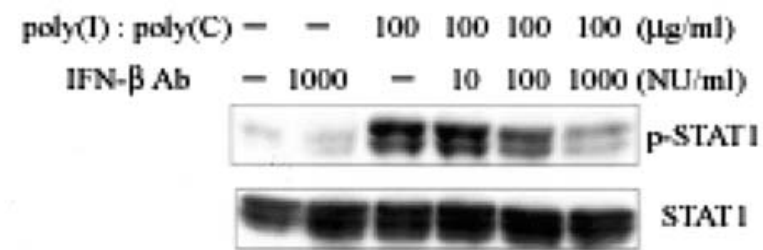

Figure 3. Poly(I):poly(C) induced STAT1 activation through IFN- $\beta$ in an autocrine fashion. (A) Cells were stimulated with $100 \mu \mathrm{g} / \mathrm{ml}$ poly(I):poly(C) for the indicated periods. The cell lysates were fractionated by $10 \%$ SDSPAGE and analyzed by Western blotting using an antibody against STAT1 or phosphor-specific STAT1 (p-STAT1). (B) E1 cells were cultured in $\alpha$ MEM containing various combinations of the indicated reagents for $3 \mathrm{~h}$, and whole cell lysates were extracted and then subjected to Western blotting using an antibody against STAT1 or p-STAT1.

poly(I):poly(C)-induced TLR3 and CXCL10 mRNA expression, E1 cells were incubated with $100 \mu \mathrm{g} / \mathrm{ml}$ of poly(I):poly(C) for $6 \mathrm{~h}$ in the presence or absence of antiIFN- $\beta$ neutralizing antibody. Fig. $2 \mathrm{D}$ shows that anti-IFN- $\beta$ antibody reduced both poly(I):poly(C)-induced TLR3 and CXCL10 mRNA expression levels, indicating that poly(I):poly $(\mathrm{C})$-induced endogenous IFN- $\beta$ was responsible for this effect.

Poly(I):poly $(C)$ induced STAT1 activation, which was blocked by anti-IFN- $\beta$ neutralizing antibody in osteoblastic El cells. We next investigated whether the abundance of the transcription factor STAT1 or its tyrosine phosphorylation was affected by poly(I):poly(C) in E1 cells. E1 cells were stimulated with $100 \mu \mathrm{g} / \mathrm{ml}$ of $\operatorname{poly}(\mathrm{I}): \operatorname{poly}(\mathrm{C})$ for various periods. As expected, the abundance of STAT1 was not changed by stimulation with poly(I):poly(C) for various periods. Poly(I):poly $(\mathrm{C})$ induced phosphorylation of STAT1 at tyrosine 701 at $3 \mathrm{~h}$ (Fig. 3A), and this effect was blocked by the addition of anti-IFN- $\beta$ neutralizing antibody in a dosedependent manner (Fig. 3B).

\section{Discussion}

IFN- $\beta$ plays an important role in the first line of host defense in mammals and is crucial for limiting the early replication and spread of viruses (15). Regulation of IFN- 3 mRNA transcription is complex, requiring the action of IRF3 in conjunction with additional transcription factors, such as NF- $\mathrm{KB}$ and AP-1 (ATF2-c-Jun) (24). To our knowledge, regulation of IFN- $\beta$ mRNA transcription in osteoblasts has not yet been elucidated. Recently, IFN- $\beta$ was suggested to be a critical cytokine for the differentiation of bone marrowderived macrophages to osteoclasts (21). Takami et al showed that poly(I):poly(C) strongly inhibited osteoclast differentiation (25). In the present study, we found that $\operatorname{poly}(\mathrm{I}) \operatorname{poly}(\mathrm{C})$ is able to induce IFN- $\beta$ mRNA in mouse osteoblastic E1 cells. This finding suggested that poly(I):poly(C) interacts with osteoblasts and inhibits osteoclastogenic bone resorption through induction of IFN- $\beta$, which is consistent with results of a previous study (25). These results demonstrate that osteoblasts have the ability to sense viral pathogens and that they maintain bone homeostasis by inhibiting osteoclastogenesis.

TLR3 recognizes double-stranded RNA and its mimic poly(I):poly(C) (8). Indeed, we found that TLR3 was expressed in E1 cells. In support of our findings, it has been reported that TLR3 mRNA was constitutively expressed in primary mouse osteoblasts (26). Our study revealed that poly(I):poly(C) up-regulated TLR3 expression in E1 cells. Doyle et al (23) reported that treatment of murine bonederived macrophages with a TLR3 ligand induced TLR3 mRNA expression. They also reported that stimulating macrophages with IFN- $\beta$ resulted in a dose-dependent upregulation of TLR3 mRNA. In the present study, we demonstrated that IFN- $\beta$ induced expression of TLR 3 mRNA in $\mathrm{E} 1$ cells, which was partially inhibited by an anti-IFN- $\beta$ neutralizing antibody. These results indicate that the release of IFN- $\beta$ from E1 cells by poly(I):poly(C) stimulation caused

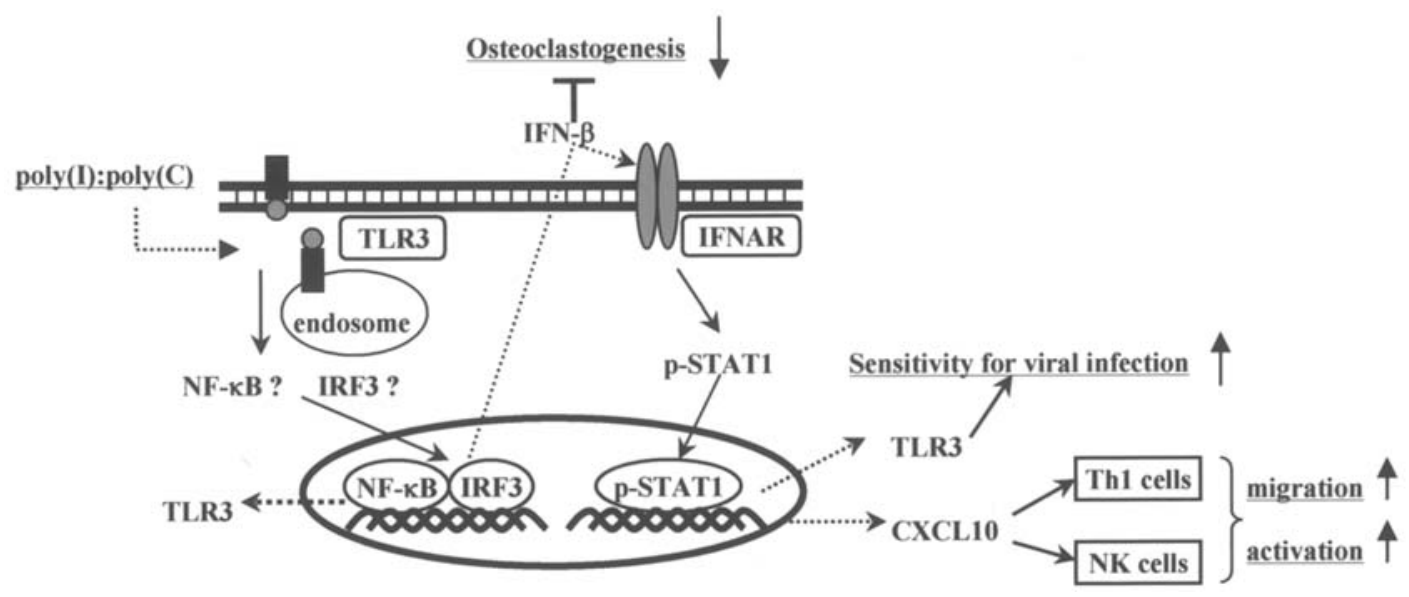

Figure 4. Schematic model of the results of poly(I):poly(C)-provoked mouse osteoblastic cell reaction. 
up-regulation of TLR3 in an autocrine manner. We also demonstrated that TLR3 mRNA was slightly up-regulated as early as $1 \mathrm{~h}$ after treatment of E1 cells with poly(I):poly(C). Therefore, another signaling pathway, which is independent of IFN- $\beta$ may exist for TLR3 up-regulation by poly(I):poly(C) in E1 cells. Further studies are needed to clarify the regulation of TLR3 expression by poly(I):poly(C) in E1 cells.

The chemokine CXCL10 is involved in immune responses against a variety of viral infections. This chemokine is a ligand for the CXCR3 receptor and specifically attracts both activated type $1 \mathrm{~T}$ lymphocytes and natural killer (NK) cells (27-29). Gasper et al (22) demonstrated that osteoblasts secrete the chemokine CXCL10 when stimulated with a bacterial pathogen or bacterial products such as LPS. In the present study, we revealed that osteoblastic E1 cells expressed CXCL10 mRNA after stimulation with poly(I):poly(C), indicating the potential for osteoblasts to secrete CXCL10 in response to viral infection. Therefore, these results suggest that osteoblasts contribute to the initiation of cell-mediated immune responses through recruitment of Th1 or NK cells to the site of bone infection.

It is known that IFN- $\beta$ induces both TLR3 and CXCL10 mRNA leading to STAT1 phosphorylation on bone marrow macrophages (23). In the present study, we revealed that poly(I):poly(C) induced STAT1 activation on osteoblastic E1 cells and this effect was blocked by the addition of an antiIFN- $\beta$ neutralizing antibody. Therefore, these results suggest that both poly(I):poly(C)-induced TLR3 and CXCL10 mRNA expression was dependent on STAT1 activation.

In summary, we demonstrated the effect of poly(I):poly(C) on mouse osteoblastic MC3T3-E1 cells. It is possible that poly(I):poly(C) first induces IFN- $\beta$ mRNA through TLR3 in mouse E1 cells, which causes STAT1 activation via the IFN- $\alpha / \beta$ receptor, and then enhances both TLR3 production and CXCL10 mRNA expression (Fig. 4). Our results indicate that osteoblasts may play a hitherto unrecognized role beyond their function in bone metabolism. Results of further studies will provide more clues to the molecular function of osteoblasts in viral infection.

\section{References}

1. Young MF, Kerr JM, Ibaraki K, Heegaard AM and Robey PG: Structure, expression, and regulation of the major noncollagenous matrix proteins of bone. Clin Orthop Relat Res 281: 275-294, 1992.

2. Chen J, Shapiro HS and Sodek J: Development expression of bone sialoprotein mRNA in rat mineralized connective tissues. $\mathrm{J}$ Bone Miner Res 7: 987-997, 1992.

3. Suda T, Takahashi N, Udagawa N, Jimi E, Gillespie MT and Martin TJ: Modulation of osteoclast differentiation and function by the new members of the tumor necrosis factor receptor and ligand families. Endocr Rev 20: 345-357, 1999.

4. Nakagawa N, Kinosaki M, Yamaguchi K, Shima N, Yasuda H, Yano K, Morinaga T and Higashio K: RANK is the essential signaling receptor for osteoclast differentiation factor in osteoclastogenesis. Biochem Biophys Res Commun 253: 395-400, 1998.

5. Yamaguchi M and Uchiyama S: Receptor activator of NF- $\mathrm{kB}$ ligand-stimulated osteoclastogenesis in mouse marrow culture is suppressed by zinc in vitro. Int J Mol Med 14: 81-85, 2004.

6. Kaisho T and Akira S: Toll-like receptor function and signaling. J Allergy Clin Immunol 117: 979-987, 2006.

7. Schwandner R, Dziarski R, Wesche H, Rothe M and Kirschning CJ: Peptidoglycan- and lipoteichoic acid-induced cell activation is mediated by Toll-like receptor 2. J Biol Chem 274: 17406-17409, 1999.
8. Alexopoulou L, Holt AC, Medzhitov R and Flavell RA: Recognition of double-stranded RNA and activation of NF- $\mathrm{KB}$ by Toll-like receptor 3. Nature 413: 732-738, 2001.

9. Poltorak A, He X, Smirnova I, Liu MY, Van Huffel C, Du X, Birdwell D, Alejos E, Silva M, Galanos C, Freudenberg M, Ricciardi-Castagnoli P, Layton B and Beutler B: Defective LPS signaling in $\mathrm{C} 3 \mathrm{H} / \mathrm{HeJ}$ and $\mathrm{C} 57 \mathrm{BL} / 10 \mathrm{ScCr}$ mice: mutations in Tlr4 gene. Science 282: 2085-2088, 1998.

10. Hayashi F, Smith KD, Ozinsky A, Hawn TR, Yi EC, Goodlett DR, Eng JK, Akira S, Underhill DM and Aderem A: The innate immune response to bacterial flagellin is mediated by Toll-like receptor 5. Nature 410: 1099-1103, 2001

11. Hemmi H, Takeuchi O, Kawai T, Kaisho T, Sato S, Sanjo H, Matsumoto M, Hoshino K, Wagner H, Takeda K and Akira S: A Toll-like receptor recognizes bacterial DNA. Nature 408: $740-745,2000$.

12. Fujisawa H, Kondo S, Wang B, Shivji GM and Sauder DN: The expression and modulation of IFN $-\alpha$ and IFN- $\beta$ in human keratinocytes. J Interferon Cytokine Res 17: 721-725, 1997.

13. Satomi H, Wang B, Fujisawa $H$ and Otsuka F: Interferon- $B$ from melanoma cells suppresses the proliferations of melanoma cells in an autocrine manner. Cytokine 18: 108-115, 2002.

14. Tohyama M, Dai X, Sayama K, Yamasaki K, Shirakata Y, Hanakawa Y, Tokumaru S, Yahata Y, Yang L, Nagai H, Takashima A and Hashimoto K: dsRNA-mediated innate immunity of epidermal keratinocytes. Biochem Biophys Res Commun 335: 505-511, 2005.

15. Einhorn S, Eldor A, Vlodavsky I, Fuks Z and Panet A: Production and characterization of interferon from endothelial cells. J Cell Physiol 122: 200-204, 1985.

16. Samuel CE: Antiviral actions of interferons. Clin Microbiol Rev 14: 778-809, 2001.

17. Stark GR, Kerr IM, Williams BR, Silverman RH and Schreiber RD: How cells respond to interferons. Annu Rev Biochem 67: 227-264, 1998.

18. Taniguchi T, Ogasawara K, Takaoka A and Tanaka N: IRF family of transcription factors as regulators of host defense. Annu Rev Immunol 19: 623-655, 2001.

19. Ducy P, Schinke T and Karsenty G: The osteoblast: a sophisticated fibroblast under central surveillance. Science 289: 1501-1504, 2000.

20. Teitelbaum SL: Bone resorption by osteoclasts. Science 289: 1504-1508, 2000.

21. Takayanagi H, Kim S, Matsuo K, Suzuki H, Suzuki T, Sato K, Yokochi T, Oda H, Nakamura K, Ida N, Wagner EF and Taniguchi T: RANKL maintains bone homeostasis through cFos-dependent induction of interferon-beta. Nature 416: 744-749, 2002.

22. Gasper NA, Petty CC, Schrum LW, Marriott I and Bost KL: Bacterium-induced CXCL10 secretion by osteoblasts can be mediated in part through toll-like receptor 4. Infect Immun 70: 4075-4082, 2002.

23. Doyle SE, O'Connell R, Vaidya SA, Chow EK, Yee K and Cheng G: Toll-like receptor 3 mediates a more potent antiviral response than Toll-like receptor 4. J Immunol 170: 3565-3571, 2003.

24. Levy DE, Marie I and Prakash A: Ringing the interferon alarm: differential regulation of gene expression at the interface between innate and adaptive immunity. Curr Opin Immunol 15: $52-58,2003$.

25. Takami M, Kim N, Rho J and Choi Y: Stimulation by toll-like receptors inhibits osteoclast differentiation. J Immunol 169: 1516-1523, 2002.

26. Kikuchi T, Matsuguchi T, Tsuboi N, Mitani A, Tanaka S, Matsuoka M, Yamamoto G, Hishikawa T, Noguchi T and Yoshikai Y: Gene expression of osteoclast differentiation factor is induced by lipopolysaccharide in mouse osteoblasts via Tolllike receptors. J Immunol 166: 3574-3579, 2001.

27. Cinatl J Jr, Michaelis M, Morgenstern B and Doerr HW: Highdose hydrocortisone reduces expression of the pro-inflammatory chemokines CXCL8 and CXCL10 in SARS coronavirusinfected intestinal cells. Int J Mol Med 15: 323-327, 2005.

28. Rossi D and Zlotnik A: The biology of chemokines and their receptors. Annu Rev Immunol 18: 217-242, 2000.

29. Loetscher M, Gerber B, Loetscher P, Jones SA, Piali L, Clark-Lewis I, Baggiolini M and Moser B: Chemokine receptor specific for IP10 and mig: structure, function, and expression in activated T-lymphocytes. J Exp Med 184: 963-969, 1996. 